\title{
Analysis of duplication in the Spanish durum wheat collection maintained in the CRF-INIA on the basis of agro-morphological traits and gliadin proteins
}

\author{
Magdalena Ruiz* and Edurne Aguiriano \\ Instituto Nacional de Investigacion y Tenologia Agraria y Alimentaria, Centro de Recursos Fitogeneticos, \\ Autovia de Aragon, Km 36, Apdo. 1045, 28800-Alcala de Henares, Madrid, Spain; *Author for \\ correspondence (e-mail: mruiz@inia.es; phone: +34 91881 9286; fax: +34918819287)
}

Key words: Agro-morphological traits, Duplicates, Durum wheat, Genebank, Gliadins, Triticum durum

\begin{abstract}
A total of 106 potential duplicate cases involved 277 accessions were detected on the basis of passport data in the durum wheat collection maintained in the CRF-INIA. Similarity between accessions was measured by agro-morphological traits. The $90 \%$ of the agro-morphological duplication were verified with gliadin proteins, allowing identification of similar material with greater refinement than agro-morphological data. However, the results indicated not to decide for rationalisation only on the basis of molecular data.
\end{abstract}

\section{Introduction}

Unwanted duplications within collections are a problem to genebanks. Since passport data can only be used as an indication of probable duplication studies directed to the identification of duplicates often combine morphological and molecular characterisation (Maass et al. 1993; Waycott and Fort 1994; Hintum and Visser 1995; Hintum et al. 1996; Zeven et al. 1998; Huaman et al. 1999). In wheat, the endosperm proteins called gliadins serve as excellent markers for genotype identification and distinction. Their discrimination power has been performed using analysis of a large number of cultivars of different origin and relationship (Kudryavtsev et al. 1996; Metakovsky and Branlard 1998; Metakovsky et al. 2000; Ruiz et al. 2002).

The objectives of the present work were (i) to assess the value of agro-morphological (qualitative and quantitative) traits and gliadins for identification of duplicates and detection of mistakes, (ii) to study the relationship between genotypic and phenotypic variation.

\section{Material and methods}

Agro-morphological characterisation and biochemical characterisation

One hundred and six cases of potential duplicates of $T$. durum Desf. were identified on the basis of passport data. These duplicates were sown in an augmented design (Petersen 1985). All the accessions were evaluated for 25 qualitative agro-morphological characters (Table 1) and five quantitative agro-morphological traits (Table 2). For each accession, gliadins were extracted and analysed from flour milled from the same five plants used for the morphological characterisation following the method described by Lafiandra and Kasarda (1985). 
Table 1. Class partition and frequencies of each qualitative agro/morphological character for 277 Spanish durum wheat varieties.

\begin{tabular}{|c|c|c|c|c|c|}
\hline Qualitative character & Frequency & Qualitative character & Frequency & Qualitative character & Frequency \\
\hline Vegetative & & Inflorescence (Cont.) & & Inflorescence (Cont.) & \\
\hline Growth habit (young) & & Spike shape & & Glume internal hairs & \\
\hline Prostrate & 93.1 & Pyramidal & 80.1 & Weak & 99.6 \\
\hline Upright & 6.9 & Tapering & 19.9 & Strong & 0.4 \\
\hline Auricles hairiness & & Lemna awn barbs & & Glume-shoulder shape & \\
\hline Absence & 82.3 & Rough & 98.9 & Sloping & 6.9 \\
\hline Presence & 17.7 & Smooth & 1.1 & Square & 15.6 \\
\hline Auricle anthocyanin pigment & & Awn colour & & Elevated & 64.1 \\
\hline Absence & 1.8 & White & 20.0 & Indented & 13.4 \\
\hline Low & 11.6 & Black at the base & 69.5 & Glume-shoulder length & \\
\hline High & 86.6 & Red to brown & 10.5 & Narrow & 88.4 \\
\hline Flag leaf habit & & Awnedness & & Wide & 11.6 \\
\hline Erect & 9.0 & Awnless & 4.7 & Glume-beak curvature & \\
\hline Recurved & 65.0 & Awned $(3$ to $8 \mathrm{~cm})$ & 1.5 & None & 87.0 \\
\hline \multirow[t]{2}{*}{ Deflexed } & 26.0 & Long awned ( $>8 \mathrm{~cm})$ & 93.8 & Medium & 13.0 \\
\hline & & Spike density & & Glume-beak length & \\
\hline Inflorescence & & Lax & 2.2 & Very short $(<1 \mathrm{~mm})$ & 12.0 \\
\hline Anthers anthocyanin pigment & & Intermediate & 67.4 & Short $(1-2 \mathrm{~mm})$ & 59.8 \\
\hline Absence & 20.9 & Dense & 30.4 & Medium $(2-5 \mathrm{~mm})$ & 27.2 \\
\hline Presence & 79.1 & Glume hairiness & & Long $(5-10 \mathrm{~mm})$ & 0.7 \\
\hline Spike waxiness & & Absence & 70.7 & Very long $(>10 \mathrm{~mm})$ & 0.3 \\
\hline Absence & 6.5 & Presence & 29.3 & & \\
\hline Presence & 93.5 & Glume colour & & Seed & \\
\hline Mature spike habit & & White & 54.3 & Grain colour & \\
\hline Erect & 22.4 & Red to brown & 35.2 & White & 79.7 \\
\hline Semierect & 76.9 & Purple to black & 10.5 & Red & 20.3 \\
\hline Deflexed & 0.7 & Glume shape & & Grain shape & \\
\hline \multirow{6}{*}{$\begin{array}{l}\text { Spike neck shape } \\
\text { Straight } \\
\text { Flexuos }\end{array}$} & & Circular & 0.4 & Oval & 28.6 \\
\hline & 79.3 & Oval & 46.3 & Long & 71.4 \\
\hline & 20.7 & Long & 53.3 & Apical rachis hairiness & \\
\hline & & Glume length & & Weak & 98.2 \\
\hline & & Medium & 31.9 & Medium & 1.8 \\
\hline & & Long & 68.1 & & \\
\hline
\end{tabular}

\section{Statistical analysis}

Quantitative data were analysed following the methodology proposed by Petersen (1985). Qualitative and quantitative data were subjected to the multivariate statistical analysis multiple correspondence (MCA) and principal component (PCA), respectively. Genetic similarity between accessions was estimated by the cluster analysis (UPGMA aggregation method). Squared Euclidean distances, computed from the factorial axe scores were used as the input for cluster analysis.

\section{Results and discussion}

Verification of potential duplicates with qualitative agro-morphological data

A total of 60 cases of potential duplicates affecting 138 entries were verified in the cluster analysis with the qualitative traits, being the similarity values above $97 \%$. Accessions involved in the same duplicate presented differences in three characters at most. Flag leaf habit, mature spike habit, anthers and auricle anthocyanin pigment, and glume length 
Table 2. Mean and standard deviation of each quantitative agromorphological character for 277 Spanish durum wheat varieties.

\begin{tabular}{lrr}
\hline Quantitative character & Mean & S.D. \\
\hline Days to flower & 164.52 & 4.06 \\
Days to maturity & 206.64 & 4.51 \\
Plant height (cm) & 117.21 & 16.67 \\
Spike length (cm) & 89.58 & 12.33 \\
Spikelets per spike & 21.49 & 5.52 \\
\hline
\end{tabular}

were the most frequently characters that showed differences within duplicates. This result is in agreement with Cervera et al. (1998) in Vitis vinifera $\mathrm{L}$. using AFLPs respect to accessions with similarities higher than $90 \%$ could be considered as same varieties.

Verification of potential duplicates with qualitative and quantitative agro-morphological data

The potential duplication detected with the passport data was verified for 60 cases. Similarly to the data obtained with only the qualitative data, these duplicates presented differences in until three characters and a similarity above $97 \%$. Comparisons between both set of data showed that only eight potential duplicates verified by the qualitative data were not verified by the qualitative plus quantitative data. These duplicates were significantly different for some of the quantitative traits, particularly for days to flower and plant height (the most discriminant of the quantitative data). Moreover, six out of these eight duplicates presented high differences in gliadin composition indicating a concordance between quantitative characteristics and gliadin genotypes. On the other hand, eight potential duplicates were verified with the qualitative plus quantitative data set but not with the qualitative traits only. Six out of the eight duplicates had the same gliadin composition and the other two cases could be considered as biotypes in gliadin composition, e.g., 'Blanco de Baleares' (Figure 1, lines 4 and 5). The qualitative characters differing most frequently among these duplicate accessions were Anthers anthocyanin pigment and Auricle anthocyanin pigment, both traits affected by environmental conditions. Consequently, more characterisation data may be required for resolving these duplication cases.

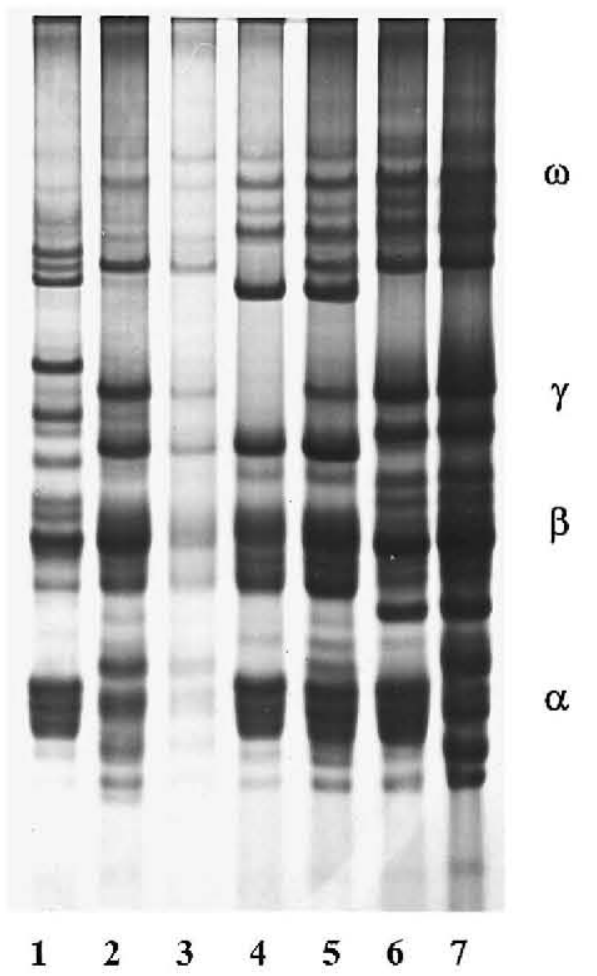

Figure 1. Electrophoretic gliadin patterns of some landrace accessions involved in potential duplicates: 'Blancal' entry code 50 (line 1), 'Blancal' entry code 51 (line 2), grain of 'Blancal' from the Spike collection (line 3), 'Blanco de Baleares' entry code 53 (line 4), 'Blanco de Baleares' entry code 52 (line 5), 'Negro' entry code 249 (line 6), 'Negro' entry code 250 (line 7). The gliadin groups $\omega, \gamma, \beta$ and $\alpha$ are indicated.

Quantitative descriptors allowed to verify some duplicate accessions not grouped in the qualitative data dendrogram and to discriminate among accessions with similar phenotype for qualitative characters. Ortiz et al. (1998) in Musa also found that some putative duplicates based on qualitative descriptors were not regarded as the same accession comparing the quantitative descriptors. According to these results, quantitative agro-morphological characters seem to be very useful to verified duplicates because they detected differences confirmed at the molecular level and not found with the qualitative characters.

\section{Relationships between qualitative and quantitative phenotype and gliadin genotypes}

We have considered the 60 potential duplicates that were verified in the qualitative plus quantitative 
dendrogram, some of them showing slightly agromorphological differences. The duplication was verified at the gliadin level in 54 cases $(90 \%)$. Waycott and Fort (1994) using RAPDs to study the duplication within a Lactuca sativa $\mathrm{L}$. collection also found concordance between morphological and molecular data in lines which showed slight morphological differences. In the present work, in one out of the six cases of disparity (morphological similarity but different in gliadin patterns) the accessions were different in one morphological character and in an $\alpha$-gliadin block coded by one allele (Kudryavtsev et al. 1996), i.e., the two accessions 249 and 250 of 'Negro' variety (Figure 1, lines 6 and 7). These two accessions can be considered as biotypes. In the rest of disparate cases, the accessions were different in no more than three agromorphological descriptors (mature spike habit and/ or some inflorescence characters). In these cases, gliadin characterisation permitted differentiation of similar material with greater refinement than agro-morphological data. Other works have also demonstrated that molecular analyses may serve as important source of information for separation of closely related accessions, especially when integrated with phenotypic measures (Waycott and Fort 1994; Hintum and Visser 1995; Cervera et al. 1998; Zeven et al. 1998).

In contrast, 14 cases of potential duplicates showing similarity in gliadin patterns were not verify in the quantitative plus qualitative dendrogram. They differed in a maximum of five agromorphological characters being the most frequent glume-beak length, days to flower, glume length, mature spike habit and/or flag leaf habit. This result revealed that accession similar on molecular data may differ in just few important agromorphological characters, e.g., two accessions derived from the 'Alaga' landrace had the same gliadin pattern and different values for seed colour and days to flower. Maass et al. (1993) found differences in isoenzyme patterns in morphologically homogeneous accessions of Arachis pintoi Krap., whereas accessions morphologically different had almost identical isoenzyme banding patterns. In the present work the probability that identical gliadin pattern was result of chance is extremely low given the number of loci screened. Probably, these accessions had been split in sub-sample in the past, each containing one morphotype, and that could be the cause of discrepancy between gliadin and agro-morphological similarity. Hintum et al. (1996) also found that some entries of Brassica oleraea derived from the same landrace, and having similar isoenzyme pattern, could be distinguished on the basis of continuous morphological differences only. Taking all these results into account we recommended not decide for rationalisation only on the basis of molecular data.

The results have shown that genetic similarity measured on the basis of molecular markers generally agreed with agro-morphological characters for very close or identical accessions, demonstrating the utility of gliadins to verify duplicates. Other works have also found that variability at both the molecular and phenotypic levels are related when the number of agro-morphological data is high (Martinez de Toda and Sancha 1997; Cervera et a1. 1998). However, in some cases duplicates clearly harbour some genetic differences (phenotypic or molecular), which may be worthwhile conserving. In consequence, to diminish redundancy in genebank collections it should be considered as duplicate accessions only those that are agromorphologically similar and possess the same electrophoretic banding pattern.

\section{Acknowledgements}

We thank R. Fite, A. Ruano and J. Rodriguez for their technical assistance. The Instituto Nacional de Investigacion y Tenologia Agraria y Alimentaria (INIA) of Spain financially supports a pre-doctoral grant for E. Aguiriano and the project OT00-05.

\section{References}

Cervera M.T., Cabezas J.A., Sancha J.C., Martínez de Toda F. and Martínez-Zapater J.M. 1998. Application of AFLPs to the characterization of grapevine Vitis vinifera $\mathrm{L}$. genetic resources. A case study with accessions from Rioja (Spain). Theor. Appl. Genet. 97: 51-59.

Hintum van Th.J.L. and Visser D.L. 1995. Duplication within and between germplasm collections. II. Duplication in four European barley collections. Genet. Resour. Crop Evol. 42: $135-145$.

Hintum van Th.J.L., Boukema I.W. and Visser D.L. 1996. Reduction of duplication in a Brassica oleracea germplasm collection. Genet. Resour. Crop Evol. 43: 343-349. 
Huaman A., Aguilar C. and Ortiz R. 1999. Selecting a Peruvian sweetpotato corecollection on the basis of morphological, eco-geographical, and disease and pest reaction data. Theor. Appl. Genet. 8: 840-844.

Kudryavtsev A.M., Boggini G., Benedettelli S. and Illichevskii N.N. 1996. Gliadin polymorphism and genetic diversity of modern Italian durum wheat. J. Genet. Breed. 50: $239-248$.

Lafiandra D. and Kasarda D.D. 1985. One and two-dimensional (two-pH) polyacrylamide gel electrophoresis in a single gel: separation of wheat proteins. Cereal Chem. 62: 314-319.

Maass B.L., Torres A.M. and Ocampo C.H. 1993. Morphological and isoenzyme characterisation of Arachis pintoi Krap. et Greg. nom. nud. germplasm. Euphytica 70: 43-52.

Martinez de Toda F. and Sancha J.C. 1997. Ampelographical characterization of red Vitis vinifera $\mathrm{L}$. cultivars preserved in Rioja. Bull. OIV 70: 220-234.

Metakovsky E.V. and Branlard G. 1998. Genetic diversity of French common wheat germplasm studied using gliadin alleles. Theor. Appl. Genet. 96(2): 209-218.

Metakovsky E.V., Gomez M., Vazquez J.F. and Carrillo J.M. 2000. High genetic diversity of Spanish common wheat as judged from gliadin alleles. Plant Breed. 119: 37-42.

Ortiz R., Madsen S. and Vuylsteke D. 1998. Classification of African plantain landraces and banana cultivars using a phenotypic distance index of quantitative descriptors. Theor. Appl. Genet. 96: 904-911.

Petersen R.G. 1985. Augmented designs for preliminary yield trials (revised). Rachis 4: 27-32.

Ruiz M., Metakovsky E.V., Rodriguez-Quijano M., Vazquez J.F. and Carrillo J.M. 2002. Assessment of storage protein variation in relation to some morphological characters in a sample of Spanish landraces of common wheat (Triticum aestivum L. ssp. vulgare). Genet. Resour. Crop Evol. 49: 371-382.

Waycott W. and Fort S.B. 1994. Differentiation of nearly identical germplasm accessions by a combination of molecular and morphologic analyses. Genome 37: 577-583.

Zeven A.C., Dehmer K.J., Gladis T., Hammer K. and Lux H. 1998. Are the duplicates of perennial kale (Brassica oleracea L. var. ramosa DC.) true duplicates as determined by RAPD analysis? Genet. Resour. Crop Evol. 45: $105-111$. 